Running title: Formulation of Solid Triheptanoin-Rich Ketogenic Diet for Rodents

\title{
Synthesis of trieheptanoin and formulation as a solid diet for rodents
}

\author{
Vladislav Semak $^{1,5}$, Jana Semaková ${ }^{2,5}$, Lyda Halbaut ${ }^{3}$, Ester Asó ${ }^{4}$, Isidro Ferrer ${ }^{4}$, \\ Ana Calpena $^{3}$, Carmen Escolano ${ }^{1}$, Jose Carlos Perales ${ }^{2, *}$
}

${ }^{1}$ Laboratory of Organic Chemistry, Faculty of Pharmacy and Institute of Biomedicine (IBUB), University of Barcelona, Barcelona, Spain

${ }^{2}$ Department of Physiological Sciences II, Faculty of Medicine, University of Barcelona, Barcelona, Spain

${ }^{3}$ Department of Pharmacy and Pharmaceutical Technology, Faculty of Pharmacy, University of Barcelona, Barcelona, Spain

${ }^{4}$ Institut de Neuropatologia, Hospital Universitari de Bellvitge, Universitat de Barcelona, Hospitalet de LLobregat, Spain

${ }^{5}$ Equally contributing authors.

* To whom correspondence should be addressed

Keywords: triheptanoin synthesis; ketogenic diet; anaplerotic diet; spreading capacity; rheological study. 


\section{Summary}

Triheptanoin enriched diets have been successfully used in the experimental treatment of various metabolic disorders. Maximal therapeutic effect is achieved in the context of a ketogenic diet where triheptanoin oil provides $30-40 \%$ of daily caloric intake. However, studies using triheptanoin-rich diets in the pre-clinical setting are hindered by the difficulty to administer to lab animals as a solid foodstuff. In the present study, we have successfully synthesized triheptanoin to the highest standards of purity from glycerol and heptanoic acid, using sulfonated charcoal, previously studied in esterification reactions by Yurui and Prager (Aust. J. Chem. 1989, 42, 1003-1005), as a catalyst. Then, triheptanoin oil was formulated as a solid, stable and palatable diet using a ketogenic base and a combination of four commercially available formulation agents; hydrophilic fumed silica, hydrophobic fumed silica, microcrystalline cellulose and talc. Diet compliance and safety was tested on C57B1/6 mice over a 15-week period, comparing overall status and body weight change. 


\section{Practical applications}

This work provides a complete description of, (i) an effective and cost-effective synthesis of triheptanoin and, (ii) the formulation of a solid, stable and palatable triheptanoin-rich $(39 \%$ of caloric intake) ketogenic diet for rodents. Rodent triheptanoin-rich diets have practical applications in pre-clinical screening of the therapeutic efficacy of triheptanoin in different rodent models of human diseases. On the other hand, using the same solidification procedure, other oils could be incorporated into rodent ketogenic diet to study its high dose/long term effect on mammal health and development. This approach could be extremely valuable as ketogenic diet is widely used clinically for epilepsy treatment. 


\section{Introduction}

In mammals, glucose is the main metabolic substrate provided to peripheral tissues and brain. However, under certain circumstances such as long term fasting or ketogenic diet administration, a liver produces four carbon (C4) ketone bodies (acetoacetate and $\beta$ hydroxybutyrate), which are preferentially utilized by peripheral organs and brain, sparing glucose for glucose-dependent tissues, such as erythrocytes and retina. Since 1990s, ketogenic diet has been used clinically to treat refractory epilepsy [6], GLUT-1 deficiency syndrome [12] and pyruvate dehydrogenase deficiency [18].

Triheptanoin (also glycerol trienanthate; 1,2,3-trienanthoylglycerol; glycerol triheptanoate, trienantin) is a special non-natural triacylglycerol composed of 3 heptanoyl chains (C7:0). If added to ketogenic diet, it is metabolized in liver to non-natural ketone bodies such as $\beta$-ketopentanoate and $\beta$-hydroxypentanoate. In peripheral organs and brain, those blood-born five carbon ketones (C5) can enter directly to the TCA (tricarboxylic acid, also Krebs) cycle via succinyl-CoA and, unlike the "classical" C4 ketone bodies, provide anaplerotic carbons. Anaplerosis is a process that replenishes TCA cycle intermediates, thus providing buildingblocks for biosynthetic pathways. Triheptanoin-derived C5 could bypass various steps of intermediary metabolism and directly "energize" mitochondria [5]. This strategy has been successfully used in treatment of metabolic disorders such as mitochondrial fatty acid oxidation defects, pyruvate carboxylase deficiency and adult polyglucosan body disease [19-21]. Interestingly, according to a recent clinical trial, even patients suffering from Huntington's chorea could benefit from triheptanoin diet [15]. In past years, basic research revealed that secondary derangement of mitochondrial metabolism accompany and worsen many complex disorders such as cancer, neurodegeneration and cardiovascular disease [6,8,10]. Intensive 
screening for possible therapeutic effects of triheptanoin in different animal models of these diseases could open new horizons for medical dietary therapy of multiple aging-associated pathologies.

Although triheptanoin has been administered parentally in some studies [11], it has best anaplerotic potential (C5 ketone production) when administered with a ketogenic diet (highprotein and fat with up to one-third of dietary calories as triheptanoin). However, studies using triheptanoin/ketogenic diets in the pre-clinical setting are hindered by the difficulty to administer to lab animals as a solid foodstuff, due to the low viscosity of triheptanoin. In the present study, we have developed an efficient synthetic protocol to produce triheptanoin from simple precursors and elaborated a palatable, low spreading and easy to administered solid diet rich in triheptanoin.

The main goal of our synthetic protocol has been to develop an efficient, economic and environmentally friendly procedure that provides considerable quantities of triheptanoin with an outstanding level of purity, of crucial importance because triheptanoin is therapeutically used in long-term, high-dose protocols. Using sulfonated charcoal, previously studied in esterification reactions by Yurui and Prager [17], as a catalyst, instead of stoichiometric reagents and halogenated solvents, synthesis was cleaner, and more efficient. Next, we produced a formulation taking into consideration not only thickening or adsorption capacity of each additive, but also their possible interaction with ketogenesis (i.e., carbohydrate content) and median lethal dose in rodents. To achieve this goal, a combination of four commercially available formulation agents has been used in this work; hydrophilic fumed silica, hydrophobic fumed silica, microcrystalline cellulose and talc. Finally, compliance and safety was performed on C57Bl/6 mice comparing overall status and body weight change for 15 weeks. 


\section{Materials and Methods}

\subsection{Chemicals}

Anhydrous glycerol (CAS: [56-81-5]) was purchased from Fluka, heptanoic acid (CAS: [111-14-8]) from Sigma-Aldrich, toluene, sodium hydroxide $(\mathrm{NaOH})$, charcoal and sulphuric acid $\left(\mathrm{H}_{2} \mathrm{SO}_{4}\right)$ from local supplier. Rheological additives (all pharmaceutical grade): hydrophilic fumed silica (AEROSIL ${ }^{\circledR}$ 200) and hydrophobic fumed silica (AEROSIL ${ }^{\circledR}$ R972) were purchased from Evonik Industries; microcrystalline cellulose (VIVAPUR $\left.{ }^{\circledR} 101\right)$ and talc (Ph Eur. / USP quality) from Quimivita S.A.

High Protein Ketogenic Diet for rodents (Test Diet - 5TJR) was purchased from IPS Product Supplies Ltd. and normal rodent chow from Harlan.

\subsection{Chemical synthesis of triheptanoin}

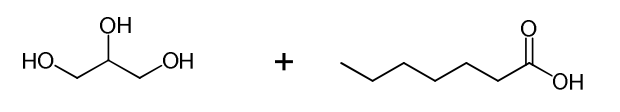

Glycerol (1.0 equiv)

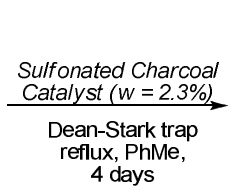
4 days

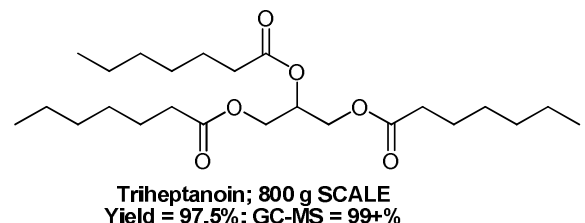

Scheme 1. Esterification reaction.

\subsubsection{General Methods}

NMR spectra were recorded in $\mathrm{CDCl}_{3}$ at $400 \mathrm{MHz}\left({ }^{1} \mathrm{H}\right)$ and $100.6 \mathrm{MHz}\left({ }^{13} \mathrm{C}\right)$, and chemical shifts are reported in $\delta$ values downfield from TMS or relative to residual chloroform $(\delta=7.26 \mathrm{ppm}, 77.0 \mathrm{ppm})$ as an internal standard. Data are reported in the following manner: chemical shift, multiplicity, coupling constant, integrated intensity. Multiplicities are reported using the following abbreviations: $t$, triplet; dd, doublet of doublets; m, multiplet; tt, triplet of triplets. Evaporation of solvents was accomplished with a rotary evaporator. Thinlayer 
chromatography was performed on $\mathrm{SiO}_{2}$ (silica gel $60 \mathrm{~F} 254$ ), and the spots were located by $1 \%$ aqueous $\mathrm{KMnO}_{4}$. Mass spectra were recorded with a LTQ spectrometer using electrospray ionization $(\mathrm{ESI}+)$ techniques.

\subsubsection{Preparation of sulfonated charcoal catalyst [9]}

A mixture of active charcoal (25 g) and sulphuric acid (75 mL, 96\%) was heated at 260 ${ }^{\circ} \mathrm{C}$ and vigorously stirred overnight $(18 \mathrm{~h})$. Then the mixture was filtered off and washed with distilled water $(1 \mathrm{~L})$ until washings gave a negative barium chloride test. The filtrate was dried at $100{ }^{\circ} \mathrm{C}$ for $24 \mathrm{~h}$.

\subsubsection{Esterification Procedure}

Sulfonated charcoal catalyst $(4.20 \mathrm{~g}, \mathrm{w}=2.3 \%$, based on glycerol) was added to a mixture of glycerol (176.85 g, $1.92 \mathrm{~mol})$, heptanoic acid (1000 g, $7.68 \mathrm{~mol}, 4.0$ equiv) and toluene $(350 \mathrm{~mL})$. The reaction mixture was heated under reflux (internal temperature: $140{ }^{\circ} \mathrm{C}$ ) with water being removed in a Dean-Stark apparatus [Annotation 1].

Work-up; Method A: After 4 days the catalyst was removed by filtration (paper; Albet $400)$ with the aid of toluene $(400 \mathrm{~mL})$. Filtrate was washed with aqueous $15 \% \mathrm{NaOH}(3 \times 300$ $\mathrm{mL})$ [Annotation 2] and with distilled water $(2 \times 50 \mathrm{~mL})$. Combined aqueous layers where extracted with toluene $(1 \times 100 \mathrm{~mL})$ and organic layer was washed with distilled water $(2 \times 20$ $\mathrm{mL})$. Combined organic extracts were dried over sodium sulphate $\left(\mathrm{Na}_{2} \mathrm{SO}_{4}\right)$, filtered and concentrated under reduced pressure to give transparent colourless liquid product. Product was 
dried in vacuum drying oven $\left(60^{\circ} \mathrm{C}, 20-30 \mathrm{mbar}, 48 \mathrm{~h}\right)$ to give transparent colourless oily liquid (802 g, 97.5\%) with purity 99+\% (GC/MS).

Work-up; Method B: $20 \mathrm{~g}$ scale experiment: The resulting filtrated was evaporated and the residue was fractionally distilled to give transparent colourless oil $\left(20.14 \mathrm{~g}, 94 \%, 190^{\circ} \mathrm{C}, 1\right.$ $\mathrm{mm} \mathrm{Hg}$ ) with purity $99+\%$ (GC/MS).

\subsubsection{Analytical data}

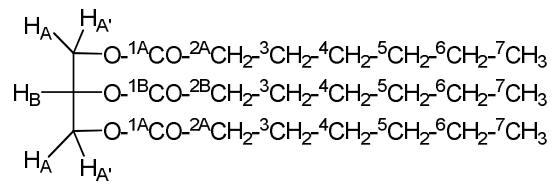

Figure 1: Triheptanoin; atom numeration for NMR assignment

${ }^{1}$ H-NMR $\left(400 \mathrm{MHz}, \mathrm{COSY}, \mathrm{CDCl}_{3}\right): \delta 0.89\left(\mathrm{t}, J=6.8 \mathrm{~Hz}, 9 \mathrm{H}, 3 \mathrm{x}-{ }^{7} \mathrm{CH}_{3}\right), 1.25-1.31(\mathrm{~m}, 18 \mathrm{H}$, $\left.3 \mathrm{x}-{ }^{4} \mathrm{CH}_{2}-{ }^{5} \mathrm{CH}_{2}{ }^{-}{ }^{6} \mathrm{CH}_{2}-\right), 1.61\left(\mathrm{~m}, 6 \mathrm{H}, 3 \mathrm{x}-{ }^{3} \mathrm{CH}_{2}-\right), 2.31$ (m, 6H, 3x $\left.{ }^{2} \mathrm{CH}_{2}-\right), 4.15$ (dd, $J=11.9,6.0$ $\mathrm{Hz}, 2 \mathrm{H}, 2 \mathrm{xH}_{\mathrm{A}}$ ) $, 4.30\left(\mathrm{dd}, J=11.9,4.3 \mathrm{~Hz}, 1 \mathrm{H}, 2 \mathrm{xH}_{\mathrm{A}}\right), 5.27\left(\mathrm{tt}, J=6.0,4.3 \mathrm{~Hz}, 1 \mathrm{H}, \mathrm{H}_{\mathrm{B}}\right) \mathrm{ppm}$. ${ }^{13}$ C-NMR (100.6 MHz, HSQC, $\left.\mathrm{CDCl}_{3}\right): \delta 13.9\left(3 \mathrm{xC}-7, \mathrm{CH}_{3}\right), 22.4\left(3 \mathrm{xC}-6, \mathrm{CH}_{2}\right), 24.7(3 \mathrm{xC}-3$, $\left.\mathrm{CH}_{2}\right), 28.7\left(3 \mathrm{xC}-4, \mathrm{CH}_{2}\right), 31.3\left(3 \mathrm{xC}-5, \mathrm{CH}_{2}\right), 33.9\left(2 \mathrm{xC}-2 \mathrm{~A}, \mathrm{CH}_{2}\right), 34.1(\mathrm{C}-2 \mathrm{~B}, \mathrm{CH}), 62.0(2 \mathrm{xC}-$ A, $\left.\mathrm{CH}_{2}\right), 68.8$ (C-B, CH), 172.7 (C-1B, COOR), 173.1 (2xC-1A, COOR) ppm. IR (NaCl): 2930, 1745 (s, COOR), $1162 \mathrm{~cm}^{-1}$. GC-MS: m/z $299\left(21 ; \mathrm{C}_{17} \mathrm{H}_{31} \mathrm{O}_{4} \cdot\right), 285\left(10 ; \mathrm{C}_{16} \mathrm{H}_{29} \mathrm{O}_{4} \cdot\right), 113(100$; $\left.\mathrm{C}_{7} \mathrm{H}_{13} \mathrm{O} \cdot\right), 85\left(16 ; \mathrm{C}_{6} \mathrm{H}_{13} \cdot\right)$. Elemental Analysis: Anal. Calcd for $\mathrm{C}_{24} \mathrm{H}_{44} \mathrm{O}_{6}$ : $\mathrm{C}, 67.26 ; \mathrm{H}, 10.35$. Found: C, 67.12; H, 10.64. [Annotation 3] High Resolution Mass Spectrometry: $\left[\mathrm{C}_{22} \mathrm{H}_{48} \mathrm{NO}_{6}\right.$ $\left(\mathrm{M}^{+}+\mathrm{NH}_{4}{ }^{+}\right)$446.3474, calculated 446.3476].[Annotation 4] UV-vis $(\mathrm{EtOH})=211 \mathrm{~nm}(\mathrm{Imax})$.

TLC: $\mathrm{R}_{f}=0.26\left(\mathrm{SiO}_{2}, 2 \% \mathrm{MeOH}\right.$ in $\left.\mathrm{CH}_{2} \mathrm{Cl}\right)$. 
Annotations to the synthesis:

1. $106 \mathrm{~mL}$ of water was collected, expected amount was $103.7 \mathrm{~mL}$ of water formed during the course of reaction and the excess is from the used solvent.

2. Error: $\mathrm{C}=0.14 \% ; \mathrm{H}=0.29 \%$ when $0.40 \%$ is permitted.

3. $0.42 \mathrm{ppm}$ difference when $5 \mathrm{ppm}$ is permitted.

4. When the reaction is finished, mixture contains $1.92 \mathrm{~mol}$ of unreacted heptanoic acid. For alkali refines 2 molar excess of base was used, i.e. 3.84 mol (153.6 g). Solution 15\% (weight): $153.6 \mathrm{~g}$ of $\mathrm{NaOH}$ and $870 \mathrm{~mL}$ of water. Observation: Sodium salt of heptanoic acid can form temporal solid - soap, which is dissolved spontaneously with time.

\subsection{Pharmaceutical formulation}

\subsubsection{Food mixture preparation and storage}

The food mixtures were prepared under normalized conditions as follows: The standard ketogenic diet $(\mathrm{KD})$ was placed into a warm water bath $\left(30^{\circ} \mathrm{C}\right)$ while the rheological additives were incorporated at room temperature to the oily phase (triheptanoin) under gentle stirring. Finally the thickened oily phase was added to the standard ketogenic diet and the mixture kneaded until homogeneity. Each sample was transferred in glass recipient hermetically closed. Once left standing at room temperature they were stored in refrigerator $\left(4 \pm 1{ }^{\circ} \mathrm{C}\right)$. The mixtures were examined $48 \mathrm{~h}$ after their elaboration. All measurements were replicated three times. Results are presented as mean value \pm standard deviation.

\subsubsection{Rheological characterization}

2.3.2.1 Spreading capacity 
The spreading capacity of ketogenic diet (KD), binary mixture (BM, i.e. $72-28 \% \mathrm{KD}$ and triheptanoin) and final triheptanoin-rich ketogenic diet (TKD) was assessed. The measurement principle consists of determining the area increase of a fixed volume of product $\left(352 \mathrm{~mm}^{3}\right)$ squashed between two parallel planes, under the effect of the constant weight pressure $(200 \mathrm{~g})$ during a fixed period of time $(1 \mathrm{~min})$. For this determination an original apparatus developed in our laboratory was used [For detailed information see supplementary material].

\subsubsection{Viscosity determination and viscoelastic behaviour}

The rheological studies have been performed using the HAAKE RheoStress 1 rheometer: Haake PP60Ti plate sensor (6 cm diameter), connected to a temperature control Thermo Haake Phoenix II + Haake C25P.

Viscosity measurements at $25{ }^{\circ} \mathrm{C}$ were applied to triheptanoin and $\mathrm{BM}$. They were carried out at three different shear rates $\left(25,50\right.$ and $\left.100 \mathrm{~s}^{-1}\right)$ and recorded during $1 \mathrm{~min}$ after the corresponding three ramp-up periods ( 0 to $25 \mathrm{~s}^{-1}, 25$ to $50 \mathrm{~s}^{-1}$ and 50 to $\left.100 \mathrm{~s}^{-1}\right)$ within $1 \mathrm{~min}$.

Oscillatory tests were applied to the final TKD in order to determine the linear viscoelastic region. Oscillatory stress sweeps between 0.1 and $100 \mathrm{~Pa}$ were performed at $1 \mathrm{~Hz}$. Four different gaps between plates were tested (1, 2, 3 or $4 \mathrm{~mm})$. Frequency sweep tests were performed from 0.01 and $10 \mathrm{~Hz}$ at a constant shear stress within the linear viscoelastic region in order to determine the related variation of storage modulus $\left(G^{\prime}\right)$ and loss modulus $\left(G^{\prime \prime}\right)$ at different temperatures $\left(25,30\right.$ y $\left.35^{\circ} \mathrm{C}\right)$. Both viscoelastic moduli are defined as follows: $\mathrm{G}^{\prime}=\tau_{\mathrm{o}} / \gamma_{0} \cdot \cos \delta$ and G" $=\tau_{\mathrm{o}} / \gamma_{\mathrm{o}} \cdot \sin \delta$ (where $\tau_{\mathrm{o}}$ and $\gamma_{\mathrm{o}}$ are the amplitudes of stress and strain and $\delta$ is the phase shift between them) $[14,23,24]$. 


\subsection{Animals}

Thirty-five female, three months old C57B1/6 mice from our colony were housed under the standard conditions, with ad libitum access to water. Control group $(\mathrm{n}=12)$ received normal chow ad libitum. $\mathrm{KD}$ and $\mathrm{TKD}$ were stored at $4^{\circ} \mathrm{C}$, according to the manufacturer's recommendation. Fresh dose of KD and TKD were offered in amount $3 \mathrm{~g} /$ day/animal twice a week, unconsumed rests were discarded. Animals were observed twice a week and weighted once a week. Study protocol was approved by the University of Barcelona Animal ethical committee.

\section{Results and discussion}

\subsection{Triheptanoin synthesis from glycerol and heptanoic acid: high yield and purity.}

To the best of our knowledge the first reported ${ }^{1} \mathrm{H}$ RMN data of triheptanoin was published by Lie Ken Jie and co-workers [13]. Saturated triacylglycerols were prepared by esterification reaction of corresponding carboxylic acid with glycerol mediated by coupling reagent (dicyclohexylcarbodiimide - DCC) in dichloromethane media. Neither experimental details, nor information on yield are described. More recently Ataide and collaborators reported the chemical synthesis of tricaproin, triheptanoin and tricaprylin in the absence of both solvent and catalyst at high temperatures and under vacuum [2]. The process involved two stages under high temperature and vacuum and a 50\% molar excess of heptanoic acid. Triheptanoin was isolated in 79\% yield after purification by column chromatography (silica gel, hexane:chloroform 1:1).

There are many questions to be considered in the synthesis of acylglycerols, especially those of potential application in the food industry and as nutraceuticals. The methods explained 
above can be excluded because coupling reagent (DCC) or excess of halogenated solvents in the purification step is used. Additional problems will be with scaling-up of the reaction under vacuum, which are potentially dangerous (especially with larger set-ups) and problematic for analytical sampling.

Therefore, we have developed an alternative procedure for the synthesis of triheptanoin that involves the esterification of heptanoic acid (33\% molar excess) by glycerol in toluene under heterogeneous catalysis (sulfonated charcoal). The reaction was scaled up from $5 \mathrm{~g}$ to $800 \mathrm{~g}$ without loss of purity with yield 94-97\%. In terms of "green chemistry metrics" [3] this process can be considered as environmentally friendly, because water is the only subproduct and the catalyst can be recycled.[9] The atom economy (AE) of this process is $88.8 \%$ and carbon efficiency (CE) is $75.5 \%$. Mass intensity (MI), rigorous metrics - in which also non-binding reagents and solvents are included - is $1.85 \mathrm{~g} / \mathrm{g}$. Very good MI ratio confirms that our synthesis is highly efficient. This method to obtain highly pure triheptanoin is a clean, cost-effective, safe and easy-to-set-up.

All the analytical data $\left({ }^{1} \mathrm{H}-\mathrm{NMR},{ }^{13} \mathrm{C}-\mathrm{NMR}, \mathrm{IR}\right.$, etc. $)$ are coincident with the previously reported data. Moreover, High Resolution Mass Spectrometry and Elemental Analysis were performed. Noteworthy, the previous assignation of the ${ }^{13} \mathrm{C} R M N$ needs to be corrected due to the fact that bidimensional studies revealed that previously assigned peaks $31.32(\mathrm{C}-5)$ and 24.70 (C-3) are interchanged.

3.2 Combination of four pharmaceutical additives improves spreading capacity and viscoelastic parameters of the Triheptanoin-rich ketogenic diet (TKD). 
In 2008, a research group from Federal University of Alagoas, Brasil, fed rats during 7 weeks with anaplerotic diet based on margarine, casein and triheptanoin with weight ratio of fat:(protein+carbohydrate) 3.5:1 but energy ratio close to 7:1. Unfortunately, no details on physical properties of this diet are available [4]. To the best of our knowledge, no formulation of solid triheptanoin-rich ketogenic diet for rodents has been described to date. Direct incorporation of requested amount of triheptanoin ( 28 weight $\%$, corresponding to 39 calorie $\%$ ) into a standard rodent ketogenic diet gives dense liquid consistency, difficult to administer to animals at room temperature in dose-controlled manner. Triheptanoin oil showed Newtonian behaviour and its viscosity at $25^{\circ} \mathrm{C}$ was $14.15 \mathrm{mPa} \cdot \mathrm{s}$. In contrast, BM showed pseudoplastic rheological behavior and its viscosity decreases with shear rate: $5743 \pm 38 \mathrm{mPa} \cdot \mathrm{s}\left(25 \mathrm{~s}^{-1}\right), 3407 \pm 13 \mathrm{mPa} \cdot \mathrm{s}\left(50 \mathrm{~s}^{-1}\right)$ and $2105 \pm 8 \mathrm{mPa} \cdot \mathrm{s}\left(100 \mathrm{~s}^{-1}\right)$. Spreading capacity of the KD was $255 \pm 7 \mathrm{~mm}^{2}$ while spreading capacity of the BM was $562 \pm 11 \mathrm{~mm}^{2}$. Four additives have been added; hydrophilic fumed silica (Aerosil ${ }^{\circledR}$ 200), hydrophobic fumed silica (Aerosil ${ }^{\circledR}$ R972), microcrystalline cellulose and talc (Table 1).

The final TKD has a solid pasty texture with spreading capacity $349 \pm 24 \mathrm{~mm}^{2}$ at room temperature.

Additive content already present in KD (Powdered cellulose) as well as mouse median lethal dose (LD50) were considered when determining the maximum amount of each additive beside their thickening or adsorption capacity [1,7,16,22].

Table 1: Content of triheptanoin-rich ketogenic diet (TKD). 


\begin{tabular}{|c|c|c|c|c|c|c|c|c|}
\hline TKD Content & Parts & $\begin{array}{l}\text { Mice LD } \\
{[\mathrm{mg} / \mathrm{g}]}\end{array}$ & $\begin{array}{l}\text { Content in daily } \\
\text { food offer }{ }^{*}[\mathrm{mgl}]\end{array}$ & $\begin{array}{c}\text { Maximal daily dose/body } \\
\text { weight }^{\star \star}[\mathrm{mg} / \mathrm{g}]\end{array}$ & $\begin{array}{l}\text { Maximal average } \\
\text { [\%] Mice } L D_{50}\end{array}$ & $\begin{array}{c}\text { Caloric } \\
\text { contetnt } \\
\text { [kcal/g] }\end{array}$ & $\begin{array}{c}\text { Daily } \\
\text { energy } \\
\text { offer [kcal] }\end{array}$ & $\begin{array}{c}\text { Energy } \\
{[\%]}\end{array}$ \\
\hline $\begin{array}{l}\text { Ketogenic diet } \\
\text { (Test Diet - 5TJR) }\end{array}$ & 72 & & 1993.0 & 99.7 & & 5.2 & 10.4 & $61 \%$ \\
\hline $\begin{array}{l}\text { (in which powdered cellulose } \\
\text { content } 2.89 \% \text { ) }\end{array}$ & & 5 & 57.6 & 2.9 & $57.6 \%$ & & & \\
\hline Triheptanoin oil & 28 & & 775.0 & 38.8 & & 8.5 & 6.6 & $39 \%$ \\
\hline $\begin{array}{c}\text { Aerosil® } 200 \\
\text { (Hydrophilic fumed silica) }\end{array}$ & 1.5 & 3.2 & 41.5 & 2.1 & $65.7 \%$ & 0 & & \\
\hline $\begin{array}{c}\text { Aerosilß R972 } \\
\text { (Hydrophobic fumed silica) }\end{array}$ & 0.9 & 5 & 24.9 & 1.3 & $24.9 \%$ & 0 & & \\
\hline Microcrystalline cellulose & 2 & 5 & 55.4 & 2.8 & $55.4 \%$ & 0 & & \\
\hline Talc & 4 & n. d. & 110.7 & 5.5 & n. d. & 0 & & \\
\hline TOTAL & 108.4 & & 3000 & 150 & & & 17.0 & \\
\hline * daily food offer & \multicolumn{2}{|c|}{$3 \mathrm{~g}(17.0 \mathrm{kcal})$} & & & & & & \\
\hline${ }^{* *}$ minimal body weight & \multirow{2}{*}{\multicolumn{2}{|c|}{$20 \mathrm{~g}$}} & & & & & & \\
\hline not determ & & & & & & & & \\
\hline
\end{tabular}

According to the results of oscillatory stress sweeps, a plat gap of $2 \mathrm{~mm}$ and a constant shear stress of $2 \mathrm{~Pa}(20 \%$ of the critical value) were selected to perform the frequency sweep tests.

Oscillatory measurements applied to TKD sample showed prevalence of the elastic over the viscous behavior $\left(\mathrm{G}^{\prime}>\mathrm{G}^{\prime \prime}\right)$ at all studied temperatures $\left(25^{\circ} \mathrm{C}-35^{\circ} \mathrm{C}\right)$ in the whole frequency range. No significant differences were detected within the temperature range (Figure 2).

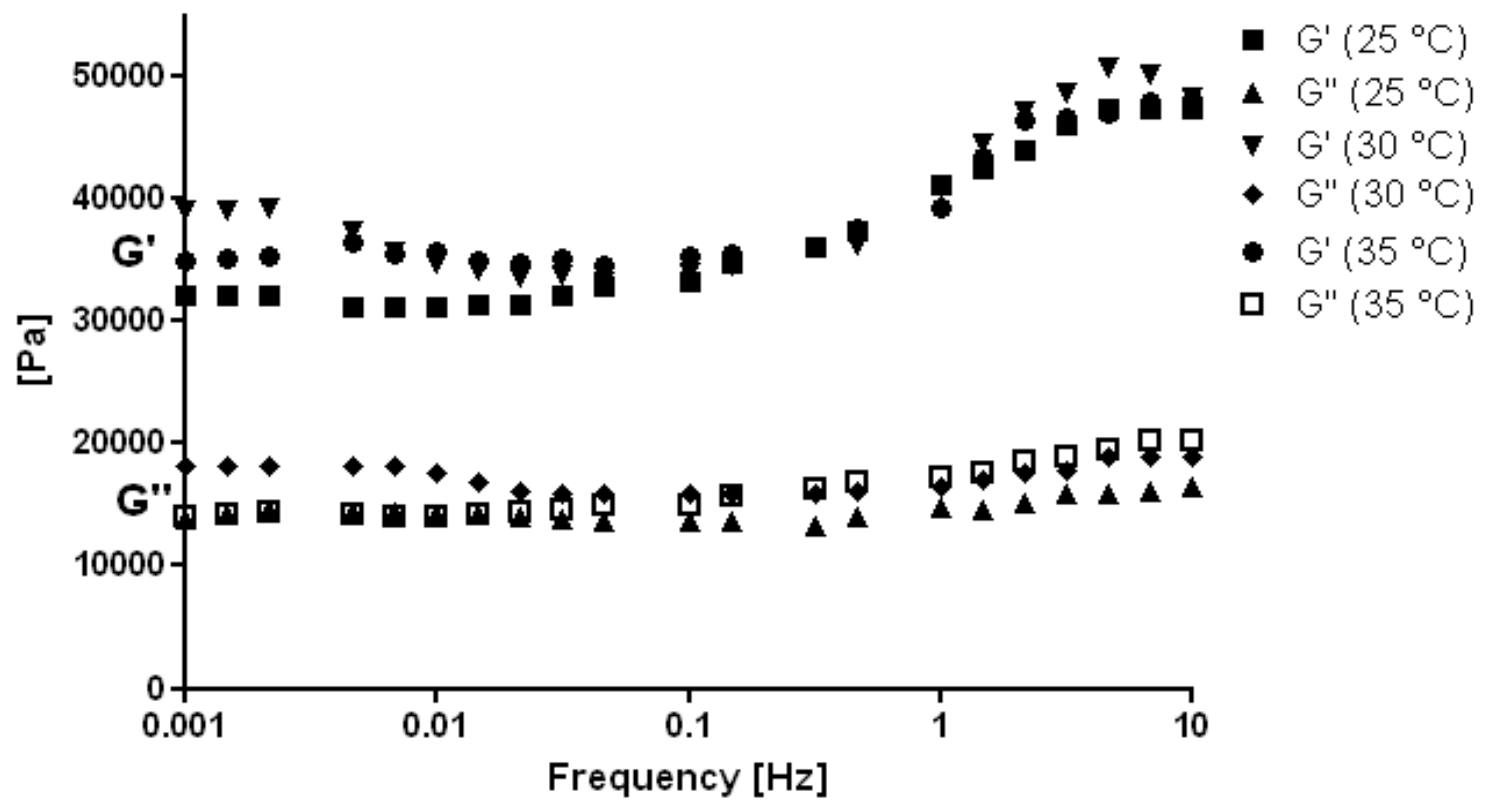


Figure 2. Frequency dependence of the storage and loss moduli for TKD. Frequency sweeps at $25^{\circ} \mathrm{C}, 30^{\circ} \mathrm{C}$ and $35^{\circ} \mathrm{C}$.

\subsection{Pilot testing in adult mice shows the diet is safe and palatable.}

Final TKD was easy to weight and administer over the cage grid and was well tolerated by the animals. There was no significant difference in body weight variation between the three groups until week nine. After 12 weeks of diet administration, animals in TKD group showed continuously lower weight gain if compared to KD and control group. No abnormality in overall status of any animal was observed (Figure 3).

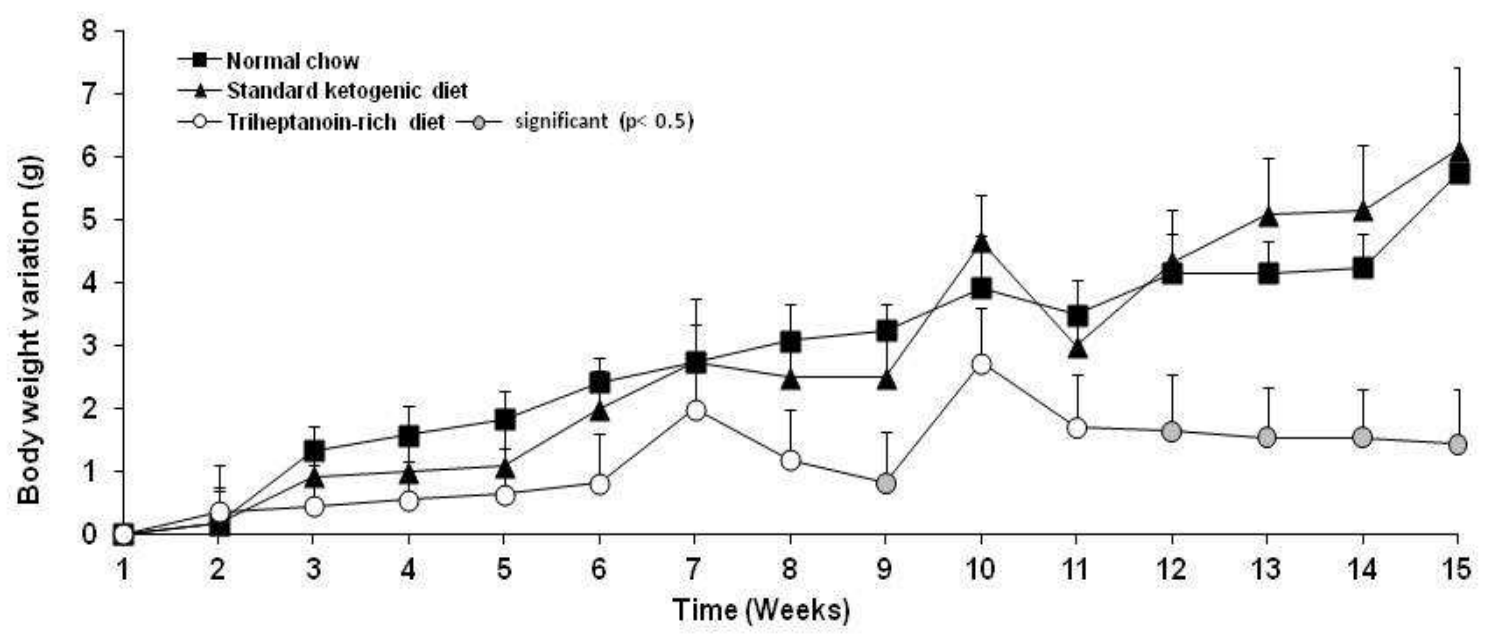

Figure 3. Animal body weight variation.

\section{Conclusions}

$>$ From the chemical viewpoint, we have developed a cost-effective procedure of triheptanoin synthesis with evident advantages: $i$ ) just small excess of heptanoic acid is used, $i i$ ) the process is metal free, iii) only environmentally friendly solvents and catalysts are involved, $i v$ ) no column 
chromatography or other purification of product is needed. Triheptanoin is isolated in $94-97 \%$ yield, with more than $99 \%$ purity (CG-MS) and no additional purification step is needed. Reaction was successfully scaled up from $5 \mathrm{~g}$ up to $800 \mathrm{~g}$.

Combination of four pharmaceutical additives improved spreading capacity and viscoelastic properties of the pilot binary mixture and resulted in solid, palatable, non-toxic, stable and easy to handle formulation of rodent Triheptanoin-rich ketogenic diet. Finally, animal testing showed that this diet is well tolerated and could be used in wide variety of chronic experiments requiring anaplerotic, triheptanoin-rich ketogenic diet.

\section{Acknowledgements:}

Financial support from the Ministry of Science and Innovation, Spain (Projects BFU2009-07506 and CTQ2009-07021/BQU) and the Agència de Gestió d'Ajuts Universitaris i de Recerca (AGAUR), Generalitat de Catalunya (Grant 2009-SGR-111) is gratefully acknowledged. V.S. and J.S. were supported by fellowships by the Ministry of Education, Spain. Sintefarma, SA (Prof. J. Bosch and Prof M. Amat) is acknowledged for providing the installations and facilities for chemical synthesis of triheptanoin. The authors are in debt to D. Sanchez Ahsen for preliminary experiments in pharmaceutical formulation performed as part of his master thesis. 
Scheme 1. Esterification reaction.

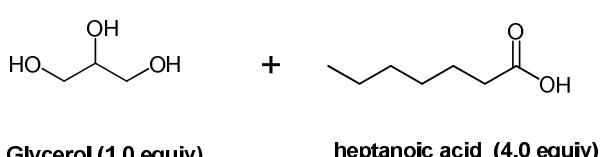

Glycerol (1.0 equiv)
Sulfonated Charcoal
Catalyst $(w=23 \%)$

Dean-Stark trap

reflux, $\mathrm{PhMe}$

4 days

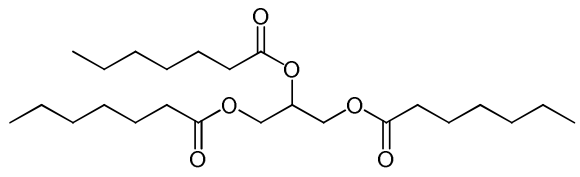

Triheptanoin; $800 \mathrm{~g} \mathrm{SCALE}$ 
Figure 1.: Triheptanoin; atom numeration for NMR assignment

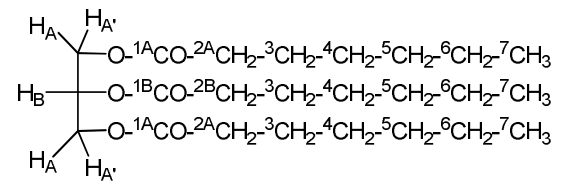


Table 1

Content of triheptanoin-rich ketogenic diet (TKD).

\begin{tabular}{|c|c|c|c|c|c|c|c|c|}
\hline TKD Content & Parts & $\begin{array}{l}\text { Mice } \mathrm{LD}_{50} \\
{[\mathrm{mg} / \mathrm{g}]}\end{array}$ & $\begin{array}{l}\text { Content in daily } \\
\text { food offer }{ }^{*}[\mathrm{mg}]\end{array}$ & $\begin{array}{l}\text { Maximal daily dose/body } \\
\text { weight }^{\star \star}[\mathrm{mg} / \mathrm{g}]\end{array}$ & $\begin{array}{l}\text { Maximal average } \\
\text { [\%] Mice } \mathrm{LD}_{50}\end{array}$ & $\begin{array}{l}\text { Caloric } \\
\text { contetnt } \\
{[\text { kcal/g] }}\end{array}$ & $\begin{array}{c}\text { Daily } \\
\text { energy } \\
\text { offer [kcal] }\end{array}$ & $\begin{array}{c}\text { Energy } \\
{[\%]}\end{array}$ \\
\hline $\begin{array}{c}\text { Ketogenic diet } \\
\text { (Test Diet - 5TJR) }\end{array}$ & 72 & & 1993.0 & 99.7 & & 5.2 & 10.4 & $61 \%$ \\
\hline $\begin{array}{l}\text { (in which powdered cellulose } \\
\text { content } 2.89 \% \text { ) }\end{array}$ & & 5 & 57.6 & 2.9 & $57.6 \%$ & & & \\
\hline Triheptanoin oil & 28 & & 775.0 & 38.8 & & 8.5 & 6.6 & $39 \%$ \\
\hline $\begin{array}{c}\text { Aerosil® } 200 \\
\text { (Hydrophilic fumed silica) }\end{array}$ & 1.5 & 3.2 & 41.5 & 2.1 & $65.7 \%$ & 0 & & \\
\hline $\begin{array}{c}\text { Aerosil® R972 } \\
\text { (Hydrophobic fumed silica) }\end{array}$ & 0.9 & 5 & 24.9 & 1.3 & $24.9 \%$ & 0 & & \\
\hline Microcrystalline cellulose & 2 & 5 & 55.4 & 2.8 & $55.4 \%$ & 0 & & \\
\hline Talc & 4 & n. d. & 110.7 & 5.5 & n. d. & 0 & & \\
\hline TOTAL & 108.4 & & 3000 & 150 & & & 17.0 & \\
\hline * daily food offer & \multicolumn{2}{|c|}{$3 \mathrm{~g}(17.0 \mathrm{kcal})$} & & & & & & \\
\hline **minimal body weight & \multicolumn{2}{|c|}{$20 \mathrm{~g}$} & & & & & & \\
\hline n. d. not determi & ned & & & & & & & \\
\hline
\end{tabular}


Figure 2. Frequency dependence of the storage and loss moduli for Trihpetanoin-rich diet. Frequency sweeps at $25^{\circ} \mathrm{C}, 30^{\circ} \mathrm{C}$ and $35^{\circ} \mathrm{C}$.

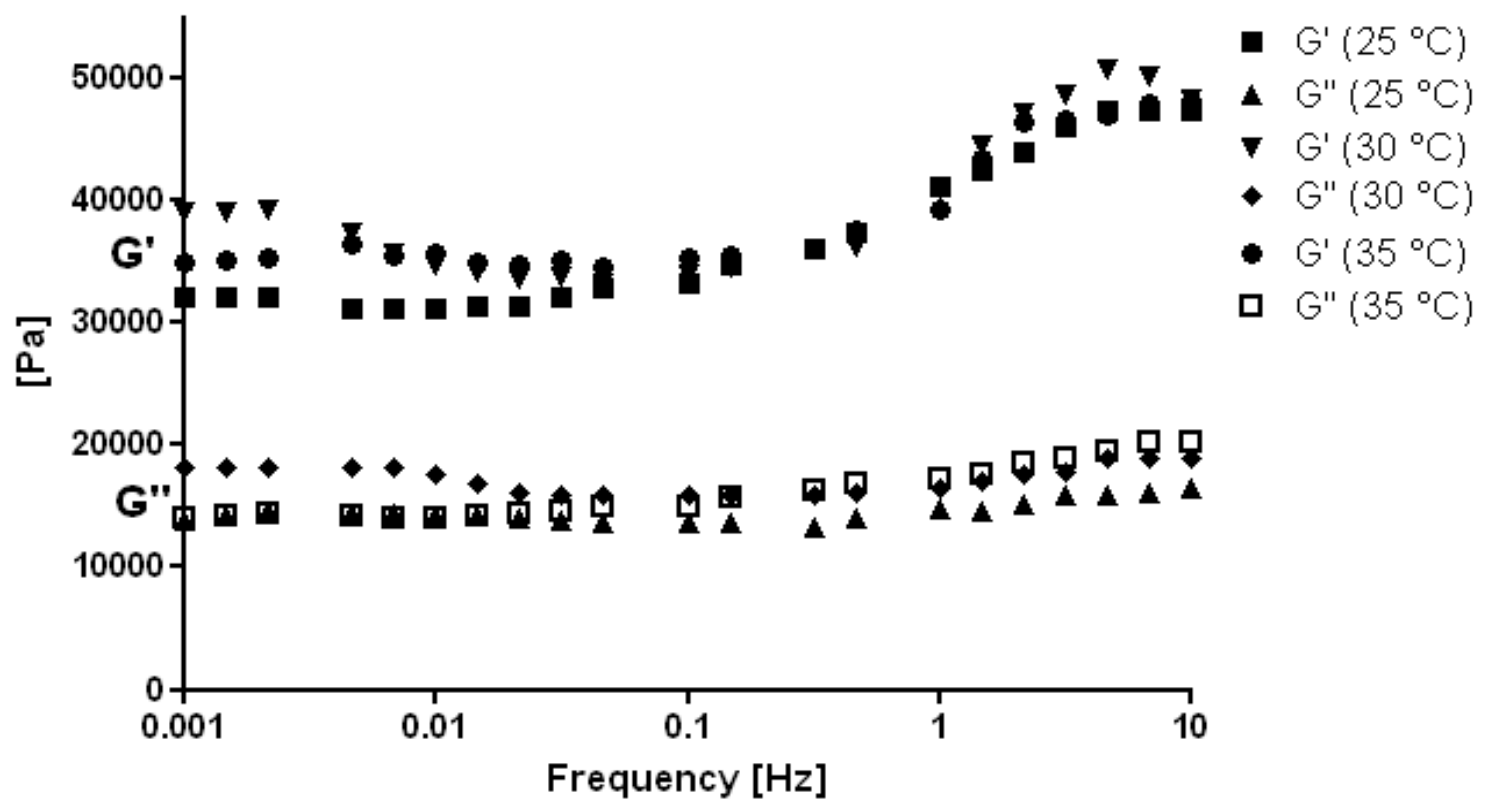


Figure 3. Animal body weight variation.

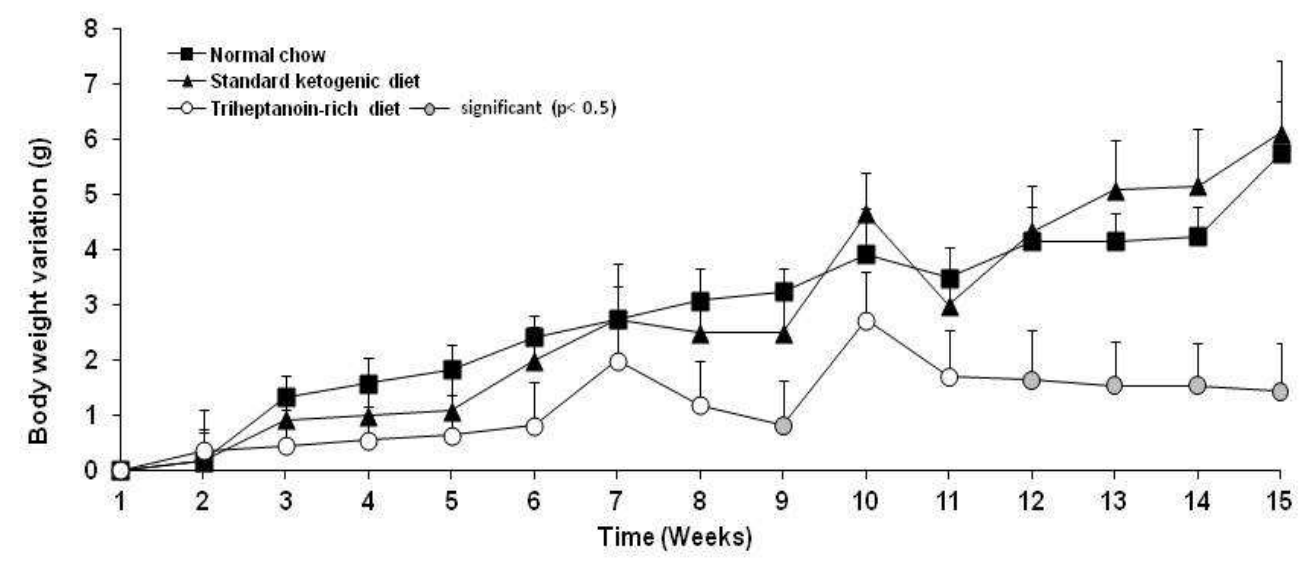

[1] Excipient Toxicity and Safety, in: Drugs and the Pharmaceutical Sciences Eds. M.L. Weiner, L.A. Kotkoskie, Marcel Dekker, Inc, New York (USA) 1999.

[2] Ataide, T.R., Lima, M.R.F., Valentim, I.B., Pinheiro, D.M., Sant'Ana, A.E.G. Chemical Synthesis of tricaproin, trienantin and tricaprylin, Int. J. Food Sci. Tech. 2007, 42, 15041508.

[3] Constable, D.J.C., Curzons, A.D., Cunningham, V.L. Metrics to 'green' chemistry which are the best?, Green Chem. 2002, 4, 521-527.

[4] de Almeida Rabello Oliveira, M., da Rocha Ataide, T., de Oliveira, S.L., de Melo Lucena, A.L., de Lira, C.E., Soares, A.A., de Almeida, C.B., Ximenes-da-Silva, A. Effects of short-term and long-term treatment with medium- and long-chain triglycerides ketogenic diet on cortical spreading depression in young rats, Neurosci Lett. 2008, 434, 66-70.

[5] Deng, S., Zhang, G.F., Kasumov, T., Roe, C.R., Brunengraber, H. Interrelations between C4 ketogenesis, C5 ketogenesis, and anaplerosis in the perfused rat liver, $J$ Biol Chem. 2009, 284, 27799-27807.

[6] Freeman, J.M., Kossoff, E.H., Hartman, A.L. The ketogenic diet: one decade later, Pediatrics. 2007, 119, 535-543.

[7] Friedman, L.J., Greenwald, C.G. Food Additives, in: Kirk-Othmer Encyclopedia of Chemical Technology. 4th ed. Ed. Wiley-Interscience 2001, pp. 435-446.

[8] Green, D.R., Galluzzi, L., Kroemer, G. Mitochondria and the autophagy-inflammationcell death axis in organismal aging, Science. 2011, 333, 1109-1112.

[9] Iranpoor, N., Firouzabadi, H., Farahi, S.J. Sulfonated charcoal as a mild and efficient catalyst for esterification and trans-esterification reactions, Sulfur Chem. 2007, 28, 581587.

[10] Jones, A.W., Yao, Z., Vicencio, J.M., Karkucinska-Wieckowska, A., Szabadkai, G. PGC1 family coactivators and cell fate: Roles in cancer, neurodegeneration, cardiovascular disease and retrograde mitochondria-nucleus signalling, Mitochondrion. 2011. 
[11] Kinman, R.P., Kasumov, T., Jobbins, K.A., Thomas, K.R., Adams, J.E., Brunengraber, L.N., Kutz, G., Brewer, W.U., Roe, C.R., Brunengraber, H. Parenteral and enteral metabolism of anaplerotic triheptanoin in normal rats, Am J Physiol Endocrinol Metab. 2006, 291, E860-866.

[12] Klepper, J. GLUT1 deficiency syndrome in clinical practice, Epilepsy Res. 2011.

[13] Lie Ken Jie, M.S.F., Lam, C.C. 1H-Nuclear magnetic resonance spectroscopic studies of saturated, acetylenic and ethylenic triacylglycerols, Chem. Phys. Lipids. 1995, 77, $155-$ 171.

[14] Martin, S.T. Rheology and Torque Rheometers, in: Pharmaceutical Extrusion Technology Eds. I. Ghebre-Sellassie, C. Martin, Marcel Dekker, Inc, New York (USA) 2003, pp. 135-151.

[15] Mochel, F., Duteil, S., Marelli, C., Jauffret, C., Barles, A., Holm, J., Sweetman, L., Benoist, J.F., Rabier, D., Carlier, P.G., Durr, A. Dietary anaplerotic therapy improves peripheral tissue energy metabolism in patients with Huntington's disease, Eur J Hum Genet. 2010, 18, 1057-1060.

[16] Owen, M.J. Release Agents, in: Kirk-Othmer Encyclopedia of Chemical Technology. 4th ed., Wiley-Interscience 2001, pp. 99-103.

[17] Prager, R.H., Yurui, Z. Preparation of carboxylate esters of polyhydric alcohols by using a sulfonated charcoal catalyst, Aust. J. Chem. 1989, 42, 1003-1005.

[18] Prasad, C., Rupar, T., Prasad, A.N. Pyruvate dehydrogenase deficiency and epilepsy, Brain Dev. 2011, 33, 856-865.

[19] Roe, C.R., Bottiglieri, T., Wallace, M., Arning, E., Martin, A. Adult Polyglucosan Body Disease (APBD): Anaplerotic diet therapy (Triheptanoin) and demonstration of defective methylation pathways, Mol Genet Metab. 2010, 101, 246-252.

[20] Roe, C.R., Mochel, F. Anaplerotic diet therapy in inherited metabolic disease: therapeutic potential, J Inherit Metab Dis. 2006, 29, 332-340.

[21] Roe, C.R., Yang, B.Z., Brunengraber, H., Roe, D.S., Wallace, M., Garritson, B.K. Carnitine palmitoyltransferase II deficiency: successful anaplerotic diet therapy, Neurology. 2008, 71, 260-264.

[22] Ruthven, D.M. Adsorption, in: Kirk-Othmer Encyclopedia of Chemical Technology. 4th ed., Wiley-Interscience 2001, pp. 251-268.

[23] Schramm, G. A practical approach to rheology and rheometry. 2nd Edition. Thermo Electron, Karlsruhe (Germany) 2004.

[24] Visintin, R.F., Lapasin, R., Vignati, E., D'Antona, P., Lockhart, T.P. Rheological behavior and structural interpretation of waxy crude oil gels, Langmuir. 2005, 21, 62406249 . 